\title{
DOCUMENTOS
}

\section{Cartas de Gabriela Mistral a Amado Nervo}

Antes del primer libro -Desolación, 1922- y todavía en él, Gabriela Mistral deja ver en su poesía el influjo manifiesto de la "mala época" en que le tocó iniciar sus actividades literarias; una época en la que, como ella observó, persistían residuos románticos —una envejecida retórica-, junto al modernismo falleciente en la segunda década de este siglo- una retórica no más eficaz que la aludida. Refiriéndose a sus años de formación literaria, la poetisa manifestó, en páginas aún inéditas:

Volviendo a mis versos, digo que me tocó en la juventud el mal trance de una mala época: el romanticismo recogía su hojazón pirotécnica, y reblandecida, y nacía el modernismo, que no era mucho mejor, aunque trajese bienes de adquisición y eliminación. Tal vez los de mi generación tuvimos la mala fortuna de salir de la mentira romántica para pasar a la máscara pintada de la nueva escuela. ${ }^{1}$

De la influencia modernista irá desprendiéndose en forma paulatina; ésta se ajeniza en la medida en que la escritora adquiere su propia expresión, de modo que en libros posteriores - Tala, Lagar- tal impulso ha retrocedido hasta un punto en que apenas es perceptible.

1 G. Mistral, "Extractos de una autobiografia". Cuaderno 103, rollo J. Biblioteca del Congreso. Agradezco a Luis Vargas Saavedra la comunicación de este fragmento. 
Tal tributo al modernismo, en el tiempo cercano a Desolación, puede ser precisada en asuntos y motivos; en modalidades del estrofismo - la preferencia por el soneto, estructura de prestigio parnasiano más que clásico español; maneras de la rima consonante y eufónica; léxico cuidado, cuando no precioso, imaginería de cuño tradicional más que visionaria, onírica; sometimiento a la 'sintáxis' más que al asintactismo, hermeticidad o alogicismo. El proceso de depuración de la herencia modernista es en Gabriela Mistral semejante -y par en la cronología-al que distancia, en el caso de César Vallejo y Pablo Neruda, a Los beraldos negros de Trilce y Poemas bumanos; a Crepusculario o Veinte poemas... de la inicial Residencia... En los tres poetas el esfuerzo por sacudirse las galas modernistas es evidente como tarea de profundización y superación de las modalidades imperantes en Hispanoamérica en las cercanías de 1920.

Las cartas de Gabriela Mistral a Nervo que aquí publicamos pertenecen a los años 1916-1917. Máxima altura del aprecio continental por el poeta mexicano, Gabriela, que ya ha conocido el triunfo con los "Sonetos de la Muerte", reside en Los Andes entre 1912 y 1918. Muerto Darío en 1916, formaba Nervo, con Lugones y Chocano - "el magnífico Chocano y el sutil Lugones" escribe la autora en $1924^{2}-$, y a pesar de incontables discrepancias literarias, el núcleo de pervivencia del Modernismo. Este se bate en retirada, bajos sus coloreados pendones, y enfrenta a otros "nuevos": López Velarde, el secreto Eguren, el promisorio Vallejo de Los beraldos negros (1918-19).

La nombradia del autor de Elevación, residente en Madrid como diplomático cuando la Mistral comienza a escribirle, era en Hispanoamérica avasallante. Sus versos, por cierto, eran sabidos de coro por mujeres y hombres de toda condición social. Tal fama sólo empezará a detetiorarse hacia 1930, con el advenimiento de la nueva poesía, enemiga de la anécdota y de "las embriagueces del corazón", en guardia contra el sospechoso prestigio de estar triste.

En 1918 Nervo es designado, por el gobierno que preside D. Venustiano Carranza, ministro plenipotenciario en Argentina, Uruguay y Paraguay. Muere en Montevideo, a poco de llegar, en 1919. Después de la muerte, novelescamente serena, que ha contado Alfonso Reyes con

\footnotetext{
2 En el prólogo a Lechuras para mujeres, de 1924.
} 
fervor, ${ }^{3}$ se acrecienta la admiración por el hombre y el poeta, más allá de la leyenda. El regreso del cadáver a México, en un barco de guerra uruguayo, al que escolta otro, argentino, da oportunidad a impresionantes manifestaciones en los puertos donde toca la fúnebre escuadra. ${ }^{4}$

Basta leer las cartas de Gabriela Mistral para aquilatar la intensidad de su admiración por Nervo, hombre y poeta confundidos. En Nervo ella vería, en sus primeros años de vida literaria, al autor que más y mejor se acercaba a su propia manera lírica, a su cosmovisión, al "neoespiritualismo" y sencillismo imperantes tras el gran boato verbal de los modernistas y los "rubéndariístas". (Cierto es que, años más tarde, esa admiración cede, y cede tanto cuanto ella se inclina a la gran veneración lírica de su madurez: la que le acerca al inconmensurable Martí). No poco le atraerían en el hombre el prestigio esotérico - ilos famosos retratos de Nervo "con sortija" y cara de vidente o demiurgo- las devociones teosóficas y las confianzas metempsicósicas, la fuerte atracción por el más allá, los muchos años de cantar a una figura amada y muerta en plena juventud, el tagorismo epocal, que ella tuvo oportunidad de ver estimulado en Chile, con traducciones en las que colaboró con varias glosas. ${ }^{5}$

De la admiración —o rendición - de Gabriela por Nervo, poseemos variado testimonio en el plano literario: todo un poema de Desolación ${ }^{6}$ -- "In memoriam", del año 1919, seguramente-, en que alaba la poesía

\footnotetext{
3 Alfonso Reyes, Tránsito de Amado Nervo. 2. "El camino de Amado Nervo". Obras completas, VIII, México: F. de C. E., 1958, p. 21.

4 Es interesante el testimonio de Fernando Paz Castillo: "...este auge de Nervo -de su obra publicada en todos los diarios y librerías de importanciay de sus versos recitados en todas las veladas, entonces frecuentes, llenó las dos primeras décadas de la presente centuria. Todavia en 1919 se conmovió profundamente nuestra sociedad, al paso de su cadáver por La Gaira, con honores militares, como a Embajador, en el crucero "Uruguay" que debía llevarlo a Veracruz, escoltado por el "9 de julio", de la marina de guerra argentina. Entre las blancas telas mortuorias parecía su rostro ya inmortal. Las manos exangües como las de un monje penitente, cruzadas en el pecho, sostenían sobre sí mismo un Cristo de marfil y un rosario [...]. Cuando salimos del barco - dejando al manso y místico Nervo entre cañones-, vimos llegar de Caracas un grupo de mujeres, en la flor de la edad y los amores, que marchaban apresuradas, como temerosas de perder la cita, trayendo en sus manos, acaso para llenar el mutismo del poeta predilecto, rosas y azucenas recién cortadas en sus matinales jardines del Avila". De la época modernista. (1892-1910). Caracas: Inciba, 1968, pp. 89-90.

5 Raúl Ramírez, Rabindranath Tagore, poeta y filósofo bindii, Santiago, 1917. Indicaba la portada la inclusión de "tres comentarios líricos en verso y tres en prosa de Gabriela Mistral". Véase R. Silva Castro, Producción de Gabriela Mistral de 1912 a 1918, Santiago: Ediciones de los Anales de la Universidad de Chile, 1957, donde se han incluido dichos comentarios, pág. 144 y ss.

6 Pảginas 26.27 de la primera edición. New York: Instituto de las Españas en los EE.UU., 1922.
} 
dulce y mejoradora del mexicano, a la vez que recuerda lo que ésta significó en su vida rica en torturas:

¡Pensar que no hay colmena que entregue tu dulzura;

que entre las lenguas de odio eras lengua de paz;

que se va el canto mecedor de la amargura,

que habrá tribulación y no responderás!

De dónde tú cantabas se me levantó el día.

Cien noches con tu verso yo me he dormido en paz...

En seguida, una estrofa de "Mis libros", " de la misma obra, en que la poesía de Nervo aparece en alzado plano de preferencias, junto a la Biblia, Dante, Francisco de Asís, Federico Mistral y Kempis, el "asceta yermo":

Te recuerdo también, deshecha de dulzuras, verso de Amado Nervo, con pecho de paloma, que me hiciste más suave la línea de la loma cuando yo te leía en mis mañanas puras...

Por último, la selección de obras de Nervo que, en 1924, incluye en Lecturas para mujeres. ${ }^{8}$ El poema, el fragmento y la selección son manifestaciones hacia afuera, en dirección pública. Las cartas, por lo mismo, encaminadas al secreto, la conversación recoleta de dos seres distantes que nunca llegaron a verse los ojos, son las que mejor traducen una ardorosa devoción. La poesía de Nervo fue para Gabriela Mistral una especie de guía de vida, asumida en toda su dirección espiritual, un indudable lenitivo para una juventud torturada. La poetisa pudo decir lo que el propio Nervo de Heredia, el de Los trofeos: "Amé a este poeta más que a ninguno otro, porque tuvo para mi alma la suprema caridad: la serenó". 9

University of Michigan

JUAN LOVELUCK

7 No incluido en la primera edición de Desolación.

8 En Lecumas..., incluyó la Mistral las siguientes composiciones: "Dar", "Irás por el camino", "Tu cuerpo", "Muera" y "Alégrate".

9 Amado Nervo, "Heredia". Obras completas, Madrid: Aguilar, t. II, 1956, p. 385 .

Nota: Agradecemos al señor licenciado don Alfonso Reyes, hijo, y a la señora Alicia Reyes, nieta del regiomontano ilustre, la autorización para reproducir estas piezas epistolares, que se conservan en los ricos archivos de la "Capilla Alfonsina", en la ciudad de México. 
Amado Nervo,

Esta carta se ha escrito muchas veces mental y materialmente: en cada libro nuevo suyo que ha alcanzado a mis manos, en cada pena mía común con la suya, en cada tarde que sugiera violentamente la confidencia emocionada. Y nunca ha ido, porque yo sé a los poetas grandes soberanamente aburridos de estas cartas sentimentales de sus lamentables discípulos, que suelen ser casi siempre su rubor...

Sin embargo hoy me escribe Jocelyn Robles ${ }^{1}$ y me dice que en carta suya a él le ha manifestado usted agradecimiento por mis fervores para su verso. ¿Es ironía Amado Nervo? ¡Usted agradecido de mí es un colmo! ¿Qué habría entonces de mí para usted, a quien debo el alma posiblemente muchísimo más que al Señor? Porque esta alma mía de hoy es más cosa suya que de otro, así sea Cristo; porque le hallo a usted en cada día y en cada llanto mío. ${ }^{2}$

Con sus versos en la boca, fui yo al amor; ellos me ayudaron a querer $\mathrm{y}$ cuando se fue el amor ellos me ayudaron a sollozar "de modo sosegado y acerbo". Hoy, que soy maestra, ellos todavía influyen mis clases y me untan los labios de una dulzura con que no nací.

¡Qué extraño, Amado Nervo, que le escriba con un temblor incontenible en las manos, y para espantar un poco esta ternura dolorosa de mi conversación con usted busque este aparato antipático que es una máquina de escribir y le envíe en filas correctas lo que habría ido en tipo irregular y sacudido? [sic]

Se le quiere a usted en Chile. No somos una raza de nervios sutiles: el más fino de los nuestros no consigue serlo de cabal manera; pero hay un buen haz de buenas almas (femeninas la mayoría) que lo siente ${ }^{3}$ a usted con una intensidad que llega a la angustia. Los otros se admiran

1 En Desolación encontramos un poema dedicado "A Joselín Robles (En el aniversario de su muerte"): "Pobre amigo, yo nunca supe/de tu semblante ni tui voz..." Obsérvese la distinta grafía del nombre.

2 En su libro Gabriela Mistral's Religious Sensibility, University of California Press, 1968, p. 78, Martin C. Taylor cita este fragmento (tomado del Epistolario: Cartas a Eugenio Labarca, edición de R. Silva Castro, Santiago, 1957), pero en una versión diferente: "¿Qué habría entonces de mi hacia usted, a quien debo el alma posiblemente tanto como a Dios, o más, ya que esta alma mía de hoy es otra cosa que la que traje a la vida y le hallo a usted a cada instante en sus pliegues recónditos?"

3 En el texto sienten, con la ene tarjada. 
como mármoles luminosos y duros; usted se adentra, se adentra por el pecho y se queda en la sangre y se hace carne del corazón. Ninguno, así se llame Darío, el Maestro, Lugones o Valencia, llega al hondor en que su verso se quedó, tatuado y vivo.

Tengo yo una frase que muchos me conocen. "Llegan muchos 'notables', pero yo no alcanzo, con mi pereza, a la estación del pueblo; pero esperen ustedes que venga un día Amado Nervo, y verán que entra conmigo a tierra chilena: a la Cumbre, ${ }^{4}$ o más allá, llego a pesar de toda mi lasitud". La frase hace reír, porque hay meses que no salgo a la puerta de mi casa...

Aprovecharé esta ocasión, que puede ser la única, de conversación con usted para pedirle una información.

Trabajando con un profesor ${ }^{6}$ en una nueva edición de sus Libros de Lectura para enseñanza secundaria, le he dado lo que [he] podido conseguir suyo apropiado para niños. Su "Gatita muerta" ha quedado en un tomo de curso preparatorio y su "iMuerta!" para otro de humanidades. He leído en una revista de México que tiene usted un volumen de poesías escolares. ¿Está agotado? ¿Dónde podría obtenerse? Sería un tesoro para nuestro trabajo. Son unos Libros [sic] que pretenden innovar en la rutina vergonzosa del viejo texto escolar y los niños chilenos le agradecerían a usted la concesión de ese dato, que nos permitirá poner más material suyo. Del "Poema del agua" hemos aprovechado mucha parte.

En 1917, fines, saldrán mis dos primeros libros, escolar uno, "profano" el otro. El primer ejemplar de los dos irá a usted. ${ }^{7}$ En tanto,

4 Recuérdese que, en los días de esta carta, G. Mistral residía en la ciudad de Los Andes; iría, pues, a recibir al poeta a la cumbre de los mismos Andes, de venir éste desde Argentina.

5 Tarjado mi calle, que es lo que escribió primeto la poetisa.

- Manuel Guzmán Maturana, cuyos Libros de lectura incluyeron cincuenta y cinco colaboraciones de G. M. en su tercera edición, Santiago de Chile, 1916 . 1917, cinco tomos. Estas obras hicieron conocido en Hispanoamérica el nombre de Gabriela Mistral, cuyo primer libro aparecerá, como es sabido, varios años después.

7 Ninguno de estos libros, por cierto, vio la luz. La poetisa fue haciéndose más y más reacia a colectar su producción en un volumen. En carta a Roberto Meza Fuentes, de 1918, le expresa: "... desde hace unos tres años probablemente [Manuel Guzmán Maturana] viene solicitándome, con esa bondad suya tan profunda como su cultura, un volumen de poesías. Le contesté la que a Prado cuando los X fueron editores y lo que a Donoso, director de la Editorial Chilena, recientemente: ique hay tantos libros de versos!" Raúl Silva Castro, Producción de G. M. de 1912 a 1918. Santiago: Ediciones AUCH, 1957, pg. 177. "Los X", son, claro, los miembros del grupo literario homónimo; además de publicar una revista, se encargaban de preparar muy pulcras ediciones de libros. Todavía en 1922, el autor anónimo de las "Palabras preliminares" de Desolación, 
y como si fuera poca heroicidad leerse esta carta inacabable, le mando unas cuantas poesías.

Yo no podría decirle, sin hacer esta carta o pretensiosa o íntima, lo que ha sido usted en la vida de mi corazón más que en la vida del arte. No hay derecho a fatigar a un hombre que no es un hermano ni siquiera un amigo con confidencias y con interjecciones que podrían parecer ridículas. Pero, pienso: ¿Es usted un extraño, Amado Nervo? Tanto he vivido con su poesía como almohada de mi corazón que me cuesta convenir en que no es usted mi amigo y en que esta carta no es para usted cosa diversa de la de un librero de provincia, por ejemplo.

Perdone usted esta temeridad de epístola, Amado Nervo. Era un verdadero remordimiento el que sentía a veces de no haberle dicho su señorío sobre mi espíritu, un pobre, un insignificante señorío, pero que debía confesarse con la vehemencia y la inmensa ternura mías hacia él.

Humilde y cariñosamente,

Gabriela Mistral.

Los Andes, Chile

Liceo de Niñas [1916].

\section{II}

Amado Nervo,

Gracias muchas veces por sus cuatro pequeñas páginas.

He estado enferma algún tiempo. En un momento pensé en que podía irme. Se me anudó la garganta al recuerdo de mi madre; pero una dulzura de anhelo satisfecho, de cumplida y alta ambición, sin definirse, estaba dentro de mi pena. Inquirí y he visto que era el gozo de haber conseguido mi nombre escrito por su mano, unas cuantas palabras suyas dichas para mí, dos instantes de sus días en que yo estuve a flor de su mente. He ahí la dulzura inmensa que me serenaba como la misma oración.

se refiere a la dificultad que hubo de vencer el Instituto de las Españas (hoy Hispanic Institute) para obtener de la poetisa los materiales que formarian su primer libro: "No era empresa fácil; porque según hemos sabido después, confirmando lo que suponíamos de antemano, era designio voluntario de la autora no coleccionar su obra". 
De nuevo: igracias! Dios le dé a usted, por su florida misericordia espiritual, una hora de dicha perfecta como la que yo tuve cuando hallé su nombre al pie de sus páginas.

Admito que haga usted suya mi alma; no es cosa de admitir, es acto consumado hace mucho tiempo, seis, más años. Es leve y dulce su señorío; va usted a dominarme, va usted a reinar sobre mis días con una vara de nardos por cetro...

Cada día, al leer con una avidez dolorosa las noticias de México, pienso en usted, amigo mío. Debe usted sufrir mucho con esta hora tan amarga y que no pasa $^{8}$ que the he detenido sobre su gran país desgraciado. ¡Qué ironías de la suerte! Usted, mexicano, resulta algo parecido a Poe yankee. $\mathrm{Y}$ ello sin intención de injuriar a su patria, que por ser suya quiero con toda mi alma. Pero es que el tipo de poeta que es lógico en aquel México de estos días es Díaz Mirón solamente. Puede que usted sea del México arcaico, supercivilizado.

Me conmovió profundamente aquel No me olvide, al final de su carta. Le explico:

Era esa una frase que en mi niñez salía a cada paso de mi boca. Creo yo, desde la edad de diez años, que se vive de amor, absoluta, completamente. No dé usted a esta frase índole literaria; dele sentido literal. Creía yo y creo que el pan cotidiano del alma es el amor. Aquel a quien ya nadie ama debe morir; muere, lógicamente. Esta verdad me la dieron desde niña las observaciones prodigiosamente vívidas que hacía yo. Cuando me hallaba entre compañeras que me querían, me sentía físicamente bien; cuando estaba al lado de mi mamá, recostada en su brazo, a veces, la sensación de bienestar era demasiado intensa para no notarla. Se me formó algo así como una poderosa superstición al respecto. Cuando estoy enferma o decaída, hago viajes por estar dos horas con una de esas personas opulentas de afecto, y sano; en diez minutos me siento mejor: he bebido, he llevado sustento a la pobre alma falleciente.

Sin petulancia, sin pretensión alguna, pues, que puede usted necesitar de mi recuerdo afectuoso aunque sea uno de esos que no necesitan viajar para morder un mendrugo de pan espiritual. Con todo el brio cálido de mi corazón quiero cada día sustentarlo con mi limpio, sereno,

8 Iá carta está escrita, claro es, en los días de la Revolución Mexicana. La poetisa no imaginaría por estas fechas que pocos años más tarde José Vasconcelos iba a invitarla a colaborar en la construcción del mundo cultural posrrevolucionario. 
fragante cariño, que quiero le dé la sensación de deleite inmenso que me daba a mi el brazo de mi madre.

Ahora que coloco la segunda hoja, pienso: ¿Pero tengo derecho a las cartas largas?

$\mathrm{Y}$ me contesto:

- Indudablemente; es muchísimo más que tu hermano.

Espero la copia de sus cantos escolares. Siento que vayan a llegar tarde para la edición que debe en agosto entrar en prensa. Siento no estar junto a usted con esta mala máquina de escribir, para copiarlos, mejor, para escribirlos al dictado.

Hasta luego, Amado Nervo. Otra vez: igracias! Perdóneme tanta mala prosa; no es literatura, es corazón, puro corazón. Olvide usted las palabras.

Gabriela Mistral

Los Andes, 1916.

\section{III}

Amado Nervo,

¡que Dios sea con Ud.! Esta frase, que es la de una monja mi pariente, es un saludo del que sólo Ud. no puede sonreir.

Tiene razón en sentir mi silencio como una cosa viva, casi tremolante de palabra y de cariño. Es lo más virgíneo que la vida nos va dejando para los que queremos este callar sagrado. Las palabras no las beben las cosas y los seres "que nos rodean sin ceñirnos"; están manchadas por este uso impuro y brutal y llego a pensar que si me encontrara algún día frente a Ud., me contentaría con mirarlo silenciosa y hondamente $y$ con recibir la dulzura y la nobleza de su mirada sobre mí.

Recibí Elevación. ${ }^{9}$ ¡Muchas veces gracias! Me dio muchos días, ${ }^{10}$ muchas tardes de éxtasis y sin embargo me dejó triste. Queda Ud. como

\footnotetext{
9 Elevacion, Madrid: Tipografía Artística Cervantes, 1917.
}

10 Tarjado de. 
al margen de la vida, quicro decir de nuestra vida. Siento su corazón en cada verso más leve que el de una paloma, liberado hasta lo inaudito le pasión, de enjundia basta. Me entristece este verso seráfico que parece decirme: el pecho de donde me he desprendido es tan ajeno al tuyo como el del mismo Francisco [de Asís]. ¡Se me va Ud.! Me aferro a Serenidad;11 para creerlo un poco "carne de mi carne y huesos de mis huesos". Pero era inevitable. Como dice Urbina ${ }^{12}$ en su semblanzatoda su obra.es semejante a un tallo de junco que, sin nudos, sin desviaciones, llega a la flor (Elevación) sutilizado pero el mismo que arrancó de Perlas negras. ${ }^{13}$ Es la misma sangre que filtran los años y la cultiva hasta entregar esta gota de milagro que es su último libro, leve y límpida más que un cristal insigne.

Eso en cuanto al espíritu; en cuanto al estilo, ¿quién soy yo para hablarle de él?

No ha llegado a las librerias la obra [Elevación]. ¿Por qué? Le han publicado versos, cedidos por Labarca ${ }^{1 \cdot 4}$ y por mí, en varias revistas, provocando lógicamente, una ansia rabiosa de leerlo todo.

Quiero decirle algo de su dedicatoria. "Protesto enérgicamente", como diría un diputado nuestro, de que un poeta - iy usted, sobre todo!se equivoque de este modo. G[abriela] $M$ [istral] es una mujer de la montaña, cobriza y salvaje, y $\mathrm{Ud}$. ha de reservar para otras -las Borrero, las Agustini ${ }^{15}$ - esas suavísimas dedicatorias. ¿Qué dirían de Ud. si se supiera su ingenua ocurrencia! Felizmente, yo lo libraré de comentarios, porque no han volteado otros dedos que los míos las hojas de Elevación.

He recibido $\mathrm{n}$ [úmer]os de Cervantes $^{\mathbf{1 6}}$ con $\mathrm{y}$ sin versos míos. Tomé una suscripción a Villaespesa; ${ }^{x 7}$ pero no sé si ha cobrado el

11 Serenidad, Madrid: Renacimiento, 1914.

12 Luis G. Urbina, 1868-1934. El poeta y prosista mexicano publicó su semblanza de Nervo en La vida literaria en México, Madrid, 1917. En Hombres y libros, de 1923, volvió a preocuparse del autor de Serenidad.

13 Perlas negras, México: Escalante, 1898. Primer libro poético de Nervo.

14 Eugenio Labarcat. Cinco cartas de Nervo a E. Labarca se encuentran en las Obras completas de aquél tomo segundo, Madrid: Aguilar, 1956, pp. 121312.14. Véase R. Silva Castro, Epistolario: Cartas a Eugenio Labarca (1915-1916), Santiago de Chile, 1957.

15 De las hermanas Borrero, Gabriela aduiraba sobre todo a Juana (18771896), de la que recogió "Las Ondinas" en Lecturas para mujeres (1924).

16 En Cervantes de Madrid colaboró G. Mistral desde 1917. Esta revista le publicó, entre otras obras, "El Pensador de Rodin", en enero de 1920.

17 Francisco Villaespesa, el errabundo poeta español que vivió entre 1877 y 1936. 
giro ni si recibió mi carta. Le hablo de esto para evitarle la molestia material de otros envíos. Ojalá Villaespesa cobre el giro y me mande la revista, que me interesa vivamente. Lo sigo a Ud. allí y yo hiciera de seguirlo por revistas y diarios, por la tierra $y$ por el cielo, un fin de mi pobre vida.

Perdóneme por el envío, gravoso para Ud., de aquella Selva lírica. ${ }^{18}$ Yo lo sé exasperado por un aluvión de libros sudamericanos que se le obliga a hojear; ipero los muchachos de aquel círculo deseaban y pedían de un modo llegar a sus manos!'19 Fui débil y accedí. Perdónemelo Ud.

¡Amado Nervo, mi único amigo ${ }^{20}$ en la soledad, hasta luego! Vivo junto a un pequeño río, en pleno campo. Es un río que habla el como debe Ud. hablar en instantes de emoción. Lo oigo esta noche con los ojos llenos de lágrimas y, hablándole, continúo interminablemente esta carta. -Lo recuerdo y lo admiro mucho. Deme Ud. un momento c [ada] mes. Escríbame dos palabras.

[Los] Andes, 1917.

GABRIELA

[P. D.] Díaz Arrieta (Alone) publicó un artículo en Pacífico [ $\mathrm{Ma}$ gazine $]^{21}$ sobre Elevación. Labarca se lo remitió a Ud. Alone es el de La Sombra inquieta. ${ }^{22}$

\section{IV}

Amado Nervo, mi querido poeta,

tengo mucha vergüenza por mi conducta para con usted; ihe callado tanto tiempo y después de recibir de su parte tan nobles demostraciones

18 En Selva lirica, antología compilada por Juan Agustín Araya (que usaba el seudónimo O. Segura Castro) y Julio Molina Núñez, Santiago de Chile, 1917. aparecieron numerosos poemas de Gabriela Mistral y de otros escritores de la época.

19 Subrayado en el original.

20 Tarjado de después de amigo, en el original.

21 Pacifico Magazine, revista de Santiago de Chile, en la cual colaboraron muchos escritores jóvenes en la época de estas cartas.

22 "Alone", es el seudónimo del crítico chileno Hernán Díaz Arrieta quien, en sus años mozos, publicó la novela arriba nombrada. 
de cordialidad! Pero usted es bueno, tan bueno como los árboles de este huerto mío, que son, con mi madre, toda la piedad que encuentro en el mundo.

Empezaré contándole cosas de gente conocida suya. ¿Recuerda usted a un joven, Jocelyn Robles, que solía escribirle? Fue él quien me dio su dirección. Sabía tanto de mi cariño por su obra que cualquier recorte de diario o revista referente a usted, por la [sic] que se pudiera "rastrear" su vida, me lo enviaba a este rincón cordillerano. Nunca lo conocí, ${ }^{23}$ pero esta fiebre por mis cultos, esta manera de ser dulce para mí, le dio mi amistad. Sin sus insinuaciones, es posible que yo nunca le hubiera escrito, Amado Nervo. Me tienen por valiente y soy una pobrecilla que tenía un temor muy grande de no ser acogida. Hace siete meses ha muerto. Rece usted por él su oración de este día.

Sobre su México. Mucho se ha hablado de ustedes en este tiempo en Chile. Un hijo del ex-ministro mexicano en Santiago dio tres o cuatro conferencias en diversos pueblos sobre la revolución. Vino luego el nombramiento de otro ministro, golpe que, según me cuenta una amiga de aquel caballero, le trajo la muerte. Ahora tenemos aquí a don Isidro Fabela ${ }^{24}$ y sé que tiene en todos los círculos, hasta en los estudiantiles, un ambiente muy propicio. Manuel Ugarte ${ }^{25}$ pasó hace días con rumbo a México, llamado por una Universidad que va a encomendarle una gira de propaganda. Ó́ a Suárez Mujica, ex-ministro de Chile en su patria estas palabras más o menos: "-Oh, los mexicanos son una gran raza y si los yankees los presentan como fantoches en revistas y periódicos es porque quieren hacerse perdonar su presión de hace quince años sobre el gran país desgraciado".

La designación de un ministro escritor para Chile me ha hecho sustentar una esperanza loca sin duda, como toda esperanza: la de que usted, Amado Nervo, llegue un día a este pais. Sin que diera usted conferencias, cosa que tal vez esté reñida con su temperamento, un simple viaje suyo por la América del Sur serviría más a México que todas las disertaciones de Ugarte. ¿Por qué lo dejan a usted allá, en

23. "Pobre amigo, yo nunca supe / de tu semblante ni tu voz; / isólo tus versos me contaron / que en tu lírico corazón / la paloma de los veinte años / tenía cuello gemidor!" "A Joselín Robles", de Desolación.

24 Fabella, erróneamente, en el original.

35 Manuel Ugarte, escritor argentino (1878-1951) que se empeñó en una campaña internacional de conferencias cuyo tema era las relaciones entre EE.UU. y la América hispánica. Su obra crítica, poco leída hoy, tiene mucho interés para conocer la literatura del modernismo, sobre todo el libro Escritores iberoamericanos del 900 . 
Europa, tanto tiempo sin ver tierra americana y hacen que acabemos por mirarlo como español, menos carne de nuestra carne de lo que es en realidad? ¡Ya ve usted, grande amigo mío, cómo yo me vuelvo capaz hasta de criticar prácticas diplomáticas y sistemas de propaganda sólo porque no quiero conformarme con no verlo nunca. ${ }^{26}$ Es que no soy de las resignadas para con la vida. Nunca le pedí bienes materiales y los espirituales que le reclamé y le reclamo son bien pocos. ¿Por qué también me ha de contestar con un ¡nunca! de madrastra este mi inmenso ruego de conocerlo a usted, de tenerlo una tarde bajo mi techo, sólo una tarde, oyéndolo?

Me cuenta usted su soledad y su preferencia por los muertos, más dulces que los vivos al corazón. Es cierto, Amado Nervo, que no hay llamado humano más poderoso que el de los pobres fantasmas. Fueron, como los vivos de hoy, superficiales y hostiles, pero la niebla desde donde miran les da ahora todas las bellezas, y la perfección está ya en sus bocas, en sus ojos, en sus hablas. ¡Cuánto le conversaría de todo esto si no lo dañara y me dañara hablándole así, ${ }^{27}$

De algún diario argentino me han recortado versos suyos que supongo son del último tiempo, todos tremolantes de infinito. ¡Ah, son muchos los poetas que hay para hablarme de la belleza de la Tierra; para parlarme de Dios no hay sino usted! ¡Qué alivio tan grande, qué dulzura nueva, a la vez suave y penctrante, los que me traen siempre, siempre, el verso suyo, la prosa suya!

Así voy vivendo con usted sin escribirle. Evito serle gravosa y estoy a su lado; sin decírselo ${ }^{28}$ estoy aplacando toda mi sed en su agua, con el silencio que conviene a la sierva. No hay adulo ni literatura en esto. Usted que es más sentidor que los álamos al viento SABE que estas palabras, con ser tan efusivas, son apenas un poco, inada más!, de la verdad profunda.

He recibido dos ejemplares de Cervantes, remitidos por usted, y un libro de un su coterráneo sobre Bélgica invadida. Hoy también escribo a él.

26 "No te vi nunca. No te veré. Mi Dios lo ha hecho. / ¿Quién te juntó las manos? ¿Quién dio, rota la voz, / la oración de los muertos al borde de tu lecho? ¿Quién te alcanzó en los ojos el estupor de Dios?", escribirá Gabriela Mistral en "In Memoriam", el poema que en Desolación consagró a la muerte de Nervo (1919).

27 Es indudable que la poetisa veía en el dolor de Nervo por su "amada inmóvil" una razón más, y poderosa, para la hemandad de espíritu que estas cartas tevelan.

28 Tarjado: "y viviendo de su alma". 
No tengo cómo agradecer el sitio dado a mis versos en la revista de Villaespesa, gracias a su simpatía generosa. Escribiré también a Villaespesa, para tomar una suscripción a Cervantes.

Dos amigos chilenos, Eduardo Batrios y Hernán Díaz Arrieta, me mandaron hace muchos meses sus libros, con el objeto de que se los remita a usted. Van por certificado. El niño que enloqueció de amor ${ }^{29}$ tiene un asunto muy simpático para mí y su autor es un hombre sencillo y talentoso, a quien estimo de verdad. Díaz Arrieta ha escrito su novela [La sombra inquieta $]^{30}$ por limpiar los huesos de una muerta a quien mucho tiene que rezar porque lo perdone otro escritor chileno que vive. en España o Francia, Leonardo Pena, ${ }^{31}$ a mi juicio un mal bombre. Fue aquella mujer muy desgraciada por su culpa y toda la literatura de Pena no lo lava de esta indignidad.

Espero tener noticias suyas, Amado Nervo. Dígame que ha perdonado mis culpas. Dos líneas cordiales, para quedar tranquila.

$Y$, una y otra vez, gracias por todo.

¡Escriba pronto!

\section{Gabr [iela] Mistral ${ }^{32}$}

P. D. Van unas cuantas poesías.

29 La conocida novela de Barrios apareció en 1915.

30 Esta novela de "Alone", Hernán Díaz Arrieta, apareció en 1916. G. Mistral escribió tres sonetos con el título de la ncvela en las pp. 37-39 de Derola. ción, primera edición, 1922, a los que sigue una "Nota de la autora": "Esta poesía es un comentario de un libro que, con ese título, escribió el fino prosista chileno Alone. El personaje principal es una artista que pasó dolorosamente por la vida".

${ }^{31}$ Leonardo Pena, pseudónimo del escritor chileno Ignacio Pérez Kallens (1875-1935).

$: 2$ La firma se lee así: "GabrMistral". 